\title{
ОСОБЕННОСТИ СОРТОВ РИСА (Oryza sativa L.) ДЛЯ ОРГАНИЧЕСКОГО ЗЕМЛЕДЕЛИЯ В СВЯЗИ С РАЗВИТИЕМ МЕТОДОВ МАРКЕРНОЙ СЕЛЕКЦИИ* \\ (обзор)
}

\author{
Ю.К. ГОНЧАРОВА 1,2 , Е.М. ХАРИТОНОВ1, Н.А. ОЧКАС 1,2 , \\ Н.И. ГАПИШКО1, Н.Н. НЕЩАДИМ 3
}

Органическое сельскохозяйственное производство активно развивается в России и в мире (S.Y. Dhurai с соавт., 2014). Темпы его роста составляют до 30 \% в год, современный рынок органических продуктов достигает более 200 млрд долларов. Выращенные по технологиям органического земледелия продукты стоят на $20 \%$, а иногда и в два раза дороже, что привлекает многих производителей. Но ценовое преимущество нивелируется снижением урожайности культур при использовании технологий органического земледелия (Г.Н. Фадькин с соавт., 2015). Повысить доходность органического земледелия может использование специализированных сортов (V. Seufert с соавт., 2012). Однако до сих пор нет четкого разделения направлений селекционной работы при создании материала для этих технологий. Цель нашего обзора - определить эффективные направления и спектр признаков, по которым должна вестись селекция при создании сортов риса для органического земледелия, а также молекулярные маркеры для ускорения селекционной работы. Сорта для органического земледелия должны обладать высокой адаптивностью к биотическим и абиотическим стрессам, конкурентоспособностью, эффективным минеральным питанием и фотосинтезом (T. Vanaja с соавт., 2013). Перечисленные признаки комплексные и в значительной мере взаимосвязаны. Так, конкурентоспособность генотипа у риса обеспечивается высокой скоростью роста, эффективным побегообразованием (кущение); морфотипом с минимальным затенением в плотном посеве; высокой эффективностью фотосинтеза, позволяющей наиболее полно использовать солнечную энергию; формированием корневой системы с высокой поглощающей способностью (E.T. Lammerts van Bueren с соавт., 2011; J.K. Goncharova с соавт., 2018). При этом повышение специфической адаптивности к комплексу стрессов требует болыше усилий и не гарантирует результата, так как внутрилокусные и межгенные взаимодействия в значительной степени нивелируют эффекты отдельных генов. В природе на растение воздействуют группы факторов, что обесценивает однонаправленную адаптивность. Специфическая устойчивость к патогенам, как правило, преодолевается ими в очень короткие сроки (А.H. Van Bruggen, 1995). Показана большая перспективность повышения общей адаптивности за счет неспецифической (полевой) устойчивости. Рассмотрены наиболее полиморфные локусы, которые у отечественных сортов риса сцеплены с генами, определяющими эффективность генетических систем, контролирующих скорость роста, фотосинтез, минеральное питание и обеспечивающих формирование неспецифической адаптивности (L. Huang c соавт., 2016). Интенсивный рост, высокая фотосинтетическая активность и эффективность минерального питания повышают жизнеспособность растений, позволяя им максимально быстро проходить фазы, чувствительные к стрессу, что сокращает вероятность повреждения экстремальными температурами или другими факторами, снижающими жизнеспособность, что актуально при органическом земледелии. Для российских сортов риса показано, что с локусами, определяющими эффективность фотосинтеза, ассоциированы микросателлитные маркеры RM154, RM600, RM550, RM347, RM240, RM154, RM509, с локусами, связанными с дифференциацей по типу минерального питания, - маркеры RM261, RM6314, RM126, RM463, RM405, RM509, RM242, с солеустойчивостью - RM463, RM245, RM242, RM3276, RM5508, RM574, RM542, с темпами роста проростка - RM261, RM405, RM463, RM242 и RM6314. В районах локализации выявленных маркеров расположены гены, определяющие энергию прорастания, устойчивость к засухе, толерантность к низким температурам, морфотип и размеры корневой системы, соотношение биомассы надземной и подземной части растения риса, стабильность мембран клеток в условиях стресса, фотосинтетический потенциал сорта (G.A. Manjunatha с соавт., 2017; J. Ali c coaвт., 2018).

Ключевые слова: рис, адаптивность, абиотические стрессы, засуха, засоление, неспецифическая устойчивость, минеральное питание, органическое земледелие.

Применение минеральных удобрений и пестицидов способствовало увеличению урожайности культур на определенном этапе развития сельско-

\footnotetext{
* Работа выполнена при поддержке гранта РНФ (№ 19-16-00064).
} 
хозяйственного производства, однако со временем проявились и негативные последствия - эрозия почв, экологические проблемы, рост заболеваемости среди населения (1-3). В связи с этим одним из актуальных направлений становиться переход на биологизированные (органические) технологии возделывания сельскохозяйственных культур (4-6), включающие применение органических удобрений и биологических препаратов, а также различные способы биологической защиты растений (7-9). Опыт хозяйств, перешедших на эти технологии, подтверждает возможность получения стабильных урожаев, особенно при использовании культур, способных к азотфиксации (1012). На начальном этапе отказ от минеральных удобрений часто приводит к снижению урожайности (13-15). Оно бывает особенно значительным (до $60 \%)$ в первый год применения природосберегающих технологий (16-18). Почвенное плодородие восстанавливается в последующие 3-4 года, за которые урожайность приближается к исходной (19-21). В это время доступность питательных веществ органических удобрений для растений повышается за счет перехода их компонентов в гумус (22-24).

У технологий органического земледелия (ТО3) есть еще одна положительная сторона - стабильность урожая в условиях стресса (засуха, засоление, температуры, выходящие за рамки нормы реакции сорта) (25-27). Применение ТО3 для интенсивных сортов часто не оправдано, поскольку их урожайность на низких фонах питания снижается более чем на 30 \% (2830). Все это подтверждает необходимость создания нового направления в селекции - создания сортов для технологий ТОЗ.

Цель настоящего обзора - рассмотреть признаки, по которым необходимо вести селекцию при создании сортов риса для органического земледелия, и определить основные методические подходы при реализации таких программ.

Характеристика сортов для органического земледелия. Признаки, которыми должен обладать сорт для выращивания по ТО3, до сих пор дискутируются (31-33), однако к ним, несомненно, относятся высокая адаптивность в условиях биотических и абиотических стрессов, конкурентоспособность генотипа, эффективность минерального питания и фотосинтеза (34-36). В то же время все перечисленные характеристики комплексные и в значительной мере взаимосвязаны. Так, высокая эффективность минерального питания и фотосинтеза обеспечивает высокую адаптивность ко всем стрессовым факторам и конкурентоспособность генотипа (37-39).

Конкурентоспособность генотипа. Высокая конкурентоспособность генотипа - один из основных признаков, обеспечивающих возможность использовать сорт при органическом земледелии. К компонентам конкурентоспособности растений риса относятся высокая скорость роста, эффективное побегообразование (кущение), морфотип, обеспечивающий минимальное затенение в плотном посеве, высокая эффективность фотосинтеза, даже при затенении позволяющая наиболее полно использовать солнечную энергию, формирование корневой системы с высокой поглощающей способностью (40-42).

На адаптивность организма к стрессам можно влиять, повышая либо специфическую адаптивность к каждому стрессу, либо неспецифическую адаптивность, которая одновременно усиливает устойчивость к различным стрессорам. Изменение специфической адаптивности требует больших усилий и не гарантирует результата, поскольку все признаки полигенные, следовательно, как внутрилокусные, так и межгенные взаимодействия могут в значительной степени нивелировать эффекты отдельных генов (43-45). В природе на растение воздействует комплекс факторов, что обесценивает 
однонаправленную адаптивность. Специфическая устойчивость к патогенам, как правило, преодолевается ими в очень короткие сроки. Поэтому с нашей точки зрения более перспективна вторая стратегия - повышение общей адаптивности (неспецифической устойчивости) за счет функционирования нескольких генетических систем, обеспечивающих эффективный фотосинтез и минеральное питания, высокую скорость роста и развития, устойчивости к засолению.

Микросателлитные маркеры, ассоциированные с локусами, определяющими эффективность фотосинтеза у российских сортов риса. Информация о молекулярных маркерах, которые сцепленных с локусами генов (quantitative traits loci, QTL), влияющих на эффективность фотосинтеза и другие признаки у сортов риса разного географического происхождения, представлена на сайте http://www.gramene.org. Однако их применимость для оценки отечественного селекционного материала должна быть подтверждена при изучении российских сортов. Необходимо показать возможность достоверного разделения контрастных по признаку групп с помощью этих маркеров $(46,47)$.

Изучение аллельного полиморфизма внутригенных SSR маркеров и маркеров, сцепленных с генами, определяющими фотосинтетический потенциал сортов риса отечественной селекции, показало наличие полиморфных локусов (рис. 1) (47).

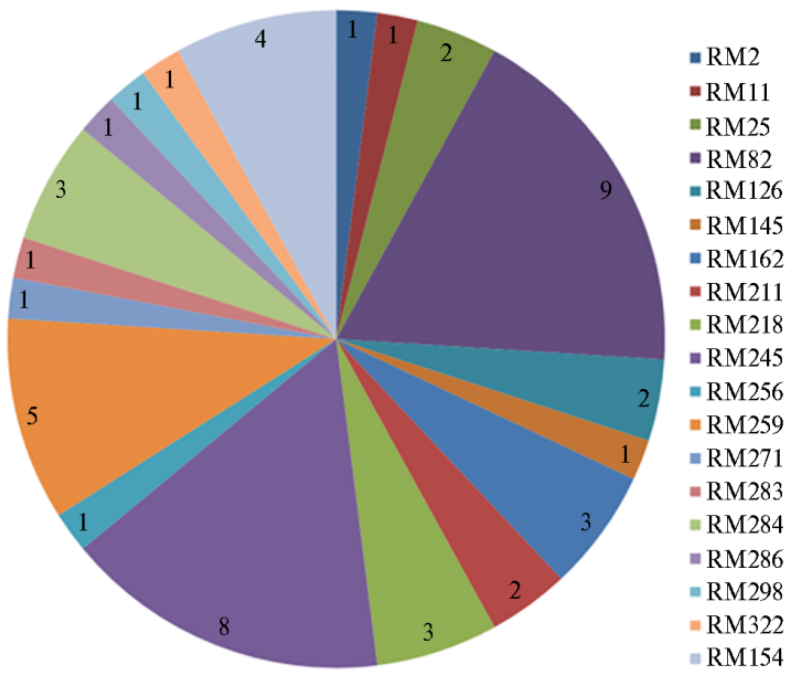

Рис. 1. Аллельный полиморфизм маркеров (указано число аллелей), связанных с эффективностью фотосинтеза у сортов риса отечественной селекции (47).

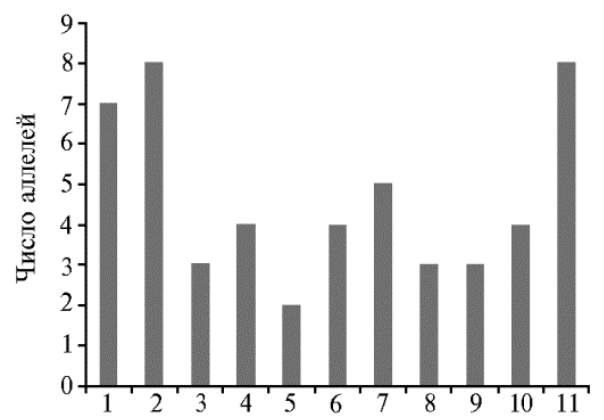

Рис. 2. Микросателлитные маркеры, ассоциированные с локусами, которые определяют эффективность фотосинтеза у российских сортов риса: 1 RM600, 2 - RM5508, 3 - RM509, 4 - RM5361, 5-RM347, 6 - RM154, 7 - RM240, 8 - RM162, 9 - RM574, 10 - RM5707, 11 - RM245 (47).

Анализ выявленного полиморфизма показал, что часть из вариабельных по продуктам амплификации маркеров разделяют группы сортов с различной эффективностью фотосинтеза на принятом в биологических исследованиях уровне значимости $(\mathrm{p} \leq 0,05)$. Три из них были сцеплены с локусами, 
определяющими формирование признака «содержание каротиноидов» (RM154, RM600, RM5508), по два маркера - с локусами, контролирущими признаки «удельная поверхностная плотность» (RM347, RM240) и «содержание хлорофилла а» (RM154, RM509). На рисунке 2 приведены сцепленные с признаком «эффективность фотосинтеза» внутригенные маркеры с максимальным числом аллелей, которые разделяют отечественные сорта риса на контрастные по признаку группы (47).

Описанные маркеры могут быть использованы для маркер-вспомогательного отбора (MAS, marker-assisted selection) по признакам, определяющим эффективность фотосинтеза у российских сортов риса. Важность генетической системы, определяющей фотосинтетический потенциал сорта, показана многими авторами (48-51). Отмечено, что сорта для ТО3, как правило, более эффективно используют свет. Они характеризуются длительным периодом фотосинтеза и высоким содержанием хлорофилла, особенно в верхних листьях. Фотосинтетическую функцию органов растений обеспечивает оптимальная архитектоника посевов. В частности, важна высота растений, их устойчивость к полеганию, а также наличие длинных и широких эректоидных листьев. При этом высота растений для ТОЗ значительно превосходит рекомендуемую для сортов, ориентированных на интенсивные технологии (в некоторых работах до 119 см, то есть на 20-30 см больше, чем для традиционного земледелия) $(44,46)$.

Районы хромосом и маркеры, перспективные для отбора по отзывчивости на минеральное питание. Потенциал использования генотипических различий по эффективности усвоения минеральных веществ огромен, поскольку между крайними проявлениями признака зафиксированы 20-кратные различия (52-54). Проблема состоит в том, что высокоурожайные сорта, как правило, не адаптированы к недостатку элементов минерального питания. Механизм приспособления растений риса к такому дефициту у разных генотипов различается и включает увеличение размеров корневой системы, интенсификацию поглощения и повышение внутренней эффективности использования удобрений. В то же время в литературе есть информация о том, что у большинства изученных генотипов последний показатель варьирует незначительно (55-57).

Отечественные сорта риса с этой точки зрения слабо изучены. Наши исследования показали высокую вариабельность урожайности у перспективных сортов риса при разных дозах азотных удобрений. Наибольшая изменчивость по признаку ( $C v=33,4 \%)$ отмечена у сорта Рапан, наиболее стабилен сорт Водопад ( $C v=15,7 \%)$. Без внесения минеральных удобрений сорта снизили урожайность в среднем на 49,05\%, при этом у интенсивных сортов (Рапан, Юбилейный 85, Наутилус) этот показатель составил 55,93 \% (варьирование от 53,33 до 58,71 \%). У сорта Водопад урожайность снизилась на $32 \%$. Другими словами, использование специализированных сортов для органического земледелия уже сейчас способно обеспечить дополнительное получение более 20 ц/га зерна риса и повысить рентабельность производства по ТОЗ в 1,5 раза (16).

При изучении реакции сортов на разные дозы азотного удобрения установлено, что без внесения удобрений по урожайности лидировал сорт Водопад (61 ц/га при средней по опыту урожайности 48,2 ц/га). Ниже средней была урожайность у сортов Наутилус (46,2 ц/га), Юбилейный 85 $(43,1$ ц/га) и Рапан (40,8 ц/га). Изменение урожайности сорта при внесении удобрений определяли по коэффициенту линейной регрессии ее связи с дозами вносимых азотных удобрений (16). 
В среднем использованное азотное удобрение в дозе 1 кг/га обеспечивало увеличение урожайности риса на 23 кг/га. При увеличении дозы удобрения зафиксировано снижение этого показателя: 32 кг/га для $\mathrm{N}_{0}-\mathrm{N}_{91}$, 21 кг/га - для $\mathrm{N}_{92}-\mathrm{N}_{137}, 15$ кг/га - для $\mathrm{N}_{138}-\mathrm{N}_{184}$ (рис. 3). Выявленная разнокачественность российских сортов позволяет вести селекцию на повышение эффективности использования элементов минерального питания при различных технологиях возделывания (58).

Ранее мы показали, что размеры корневой системы во многом определяют адаптивность образцов к недостатку минерального питания, однако не был изучен вопрос о том, использование каких молекулярных маркеров позволяет достоверно разделять отечественные образцы на контрастные группы по признаку в разные фазы вегетации (56).

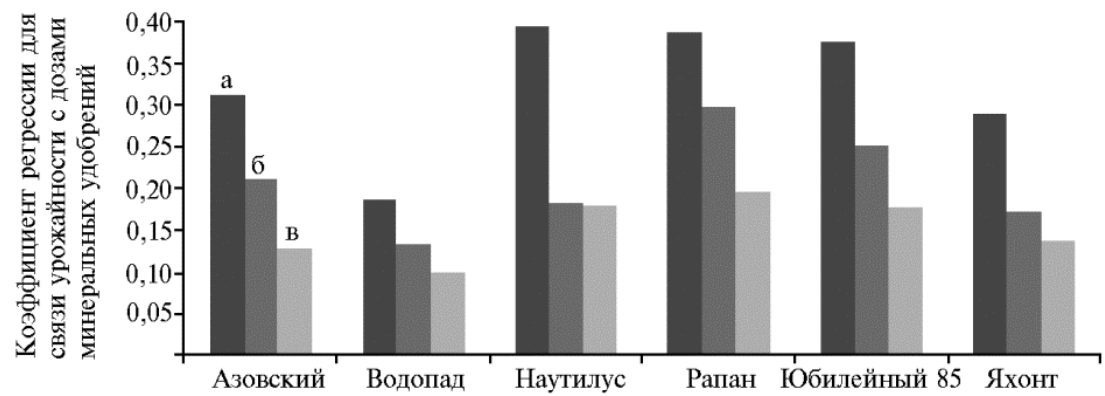

Рис. 3. Изменение урожайности у российских сортов риса в зависимости от доз азотных удобрений (по действующему веществу): а - 0-91 кг/га, б - 92-137 кг/га, в - 138-184 кг/га (экспериментальный участок ФНЦ риса, г. Краснодар, 2017-2018 годы) (16).

Исследование российских сортов риса с использованием микросателлитных маркеров показало, что размеры корневой системы определяют гены, находящиеся в 14 локусах (30), причем в разные фазы развития растений эти гены неодинаковы. Семь SSR маркеров (RM261, RM6314, RM126, RM463, RM405, RM509 и RM242) дифференцировали образцы по эффективности минерального питания в фазу всходов. Ни один из маркеров достоверно не разделял выборку образцов по эффективности минерального питания на стадии кущения. Высокая вероятность связи с признаком установлена для маркеров RM245, RM284, RM574, RM258, RM227, RM509, RM3428, RM440, RM154. Десять SSR маркеров - RM284, RM335, RM245, RM600, RM53, RM542, RM261, RM5361, RM5371 и RM6314 дискриминировали отечественные сорта риса на группы, контрастные по адаптивности к недостатку минерального питания в фазу созревания (табл. 1).

1. SSR маркеры, дискриминирующие отечественные сорта риса на контрастные группы по адаптивности к недостатку минерального питания

\begin{tabular}{|c|c|c|c|c|}
\hline Ген & Признаки & SSR маркер & Хромосома & Источник \\
\hline TRN7-1 & Число корней через 65 сут после посева & RM542 & $7-9$ & (59) \\
\hline LFSNS & $\begin{array}{l}\text { Старение листа, отношение содержания } \\
\text { хлорофилла во 2-м листе в фазу выметы- } \\
\text { вания и через } 30 \text { сут }\end{array}$ & RM 245 & $9-9$ & (60) \\
\hline$q T R N 1-2$ & Число корней через 65 сут после посева & RM600 & $1-я$ & (59) \\
\hline OSAD-JCAP & Способность к осмотической регуляции & RM284 & $8-я$ & $(61)$ \\
\hline rdgf4 LFSNS & $\begin{array}{l}\text { Старение листа, отношение содержания } \\
\text { хлорофилла во 2-м листе в фазу выметы- } \\
\text { вания и через } 30 \text { сут }\end{array}$ & RM335 & 4-я & $(62)$ \\
\hline AQEI046-LFSNS & $\begin{array}{l}\text { Старение листа, отношение содержания } \\
\text { хлорофилла во 2-м листе в фазу выметы- } \\
\text { вания и через } 30 \text { сут }\end{array}$ & RM53 & $2-9$ & $(62)$ \\
\hline qTRN4-1 & Число корней через 85 сут после посева & RM261 & 4-я & (59) \\
\hline
\end{tabular}




\begin{tabular}{|c|c|c|c|c|}
\hline \multirow[b]{2}{*}{ ЭИМП } & \multirow[b]{2}{*}{$\begin{array}{l}\text { Эффективность использования } \\
\text { минерального питания }\end{array}$} & \multirow[b]{2}{*}{ RM5371 } & \multicolumn{2}{|c|}{ Продолжение таблицы 1} \\
\hline & & & $6-9$ & $(63)$ \\
\hline ЭИМП & $\begin{array}{l}\text { Эффективность использования } \\
\text { минерального питания }\end{array}$ & RM5361 & $5-я$ & (63) \\
\hline ЭИМП & $\begin{array}{l}\text { Эффективность использования } \\
\text { минерального питания }\end{array}$ & RM6314 & 4-я & $(30,64)$ \\
\hline OSADJCAP & Способность к осмотической регуляции & RM126 & 8 -я & (61) \\
\hline qRTT9-1 & Толщина корней через 65 сут после посева & RM242 & $9-я$ & (59) \\
\hline qPHT12-1 & Высота растения & RM463 & $12-я$ & (59) \\
\hline$q F R P-12$ & Число зерен в метелке & & & \\
\hline ЭИМП & $\begin{array}{l}\text { Эффективность использования } \\
\text { минерального питания }\end{array}$ & RM509 & $5-я$ & $(63,65)$ \\
\hline$q R T V 5-1$ & Объем корней через 65 сут после посева & RM289 & 5 -я & (59) \\
\hline$q P L-5$ & Длина метелки & RM405 & $5-9$ & $(66)$ \\
\hline$q Y I-5$ & Число колосков на метелке & & & \\
\hline ЭИМП & $\begin{array}{l}\text { Эффективность использования } \\
\text { минерального питания }\end{array}$ & RM3155 & 8-я & $(30,64)$ \\
\hline
\end{tabular}

Ранее были картированы как специфические, так и неспецифические гены, усиливающие отзывчивость растений риса на минеральное питание, выявлены также SSR маркеры, которые находятся в районах локализации этих генов (67-69). Локусы, обусловливающие эффективность минерального питания у отечественных сортов, в литературе определены как отвечающие за число, объем и толщину корней через 65 сут после посева, способность к осмотической регуляции, старение листа (отношение содержания хлорофилла во 2-м листе в фазу выметывания и через 30 сут). Поскольку существует тесная корреляционная связь между размерами наземной и подземной части растений и известно плейотропное влияние многих генов, локусы, определяющие высоту растения, длину метелки, число зерен в метелке, были также отнесены к повышающим эффективность использования элементов минерального питания (70-72).

SSR маркеры, определяющие солеустойчивость российских образцов риса. SSR маркеры, достоверно разделяющие российские образцы на группы с различной солеустойчивостью в фазу цветения, приведены в таблице 2. Анализ генов, ранее картированных в районах локализации этих маркеров, показал (72), что только два из них связаны со специфическими генами устойчивости к засолению (способность к осмотической регуляции) - RM25 и RM240. Другие маркеры сцеплены с неспецифическими локусами, повышающими жизнеспособность и устойчивость к ряду стрессоров (72-75).

Маркеры, позволяющие достоверно дискриминировать контрастные по адаптивности к засолению отечественные сорта риса на основании изменения длины зародышевого корешка, не установлены. Полученный результат закономерен, поскольку адаптивность к засолению определяется работой полигенов или генных кластеров. Изученные образцы несут наборы генов, которые, действуя совместно, скрывают эффект того или иного локуса. Однако это не помешало выявить локусы, наиболее вероятно связанные с анализируемым признаком в фазу проростков, для чего порог чувствительности метода был повышен за счет увеличения уровня значимости до $\mathrm{p} \leq 0,09$ (76). На принятом уровне значимости выявлен ряд локусов, определяющих изменение длины корневой системы при засолении в начальные фазы вегетации. Группы сортов в большинстве случаев также разделяются за счет неспецифических генов, повышающих устойчивость к засолению (76). 
2. SSR маркеры, ассоциированные у отечественных сортов риса с солеустойчивостыю (72)

\begin{tabular}{|c|c|c|c|}
\hline SSR маркер & Хромосома & $\begin{array}{l}\text { Продукт амплификации, п.н. } \\
\left.\text { (температура плавления, }{ }^{\circ} \mathrm{C}\right)\end{array}$ & Признаки \\
\hline \multicolumn{4}{|c|}{ В фазу цве те ния } \\
\hline RM574 & $5-9$ & $155(55)$ & Параметры корневой системы \\
\hline RM245 & 9-я & $150(55)$ & $\begin{array}{l}\text { Эффективность фотосинтеза в период } \\
\text { созревания, период вегетации }\end{array}$ \\
\hline RM240 & $2-я$ & $132(55)$ & Осмотическая регуляция, период вегетации \\
\hline RM53 & $2-9$ & $182(55)$ & Старение листьев, период вегетации \\
\hline RM25 & $8-я$ & $146(55)$ & $\begin{array}{l}\text { Период вегетации, осмотическая } \\
\text { регуляция, старение листьев }\end{array}$ \\
\hline RM590 & 10 -я & $137(55)$ & Трещинноватость \\
\hline RM24 & $1-я$ & 192(55) & $\begin{array}{l}\text { Отношение числа корней и стеблей, период } \\
\text { вегетации, размеры листового аппарата }\end{array}$ \\
\hline RM5361 & $5-я$ & $138(55)$ & Информация в базах данных отсутствует \\
\hline RM574 & $\mathrm{B}_{5-я}^{\phi}$ а 3 y & $\begin{array}{c}\text { пр оростков по п пизна } \\
155(55)\end{array}$ & $\begin{array}{c}\text { п р и з н а к у «Д л и н а к о р н я » } \\
\text { Объем корневой системы, толщина } \\
\text { корневой системы }\end{array}$ \\
\hline RM245 & 9-я & $150(55)$ & $\begin{array}{l}\text { Фотосинтетический потенциал, } \\
\text { продолжительность вегетации }\end{array}$ \\
\hline RM542 & $7-я$ & $113(55)$ & $\begin{array}{l}\text { Объем корней, угол наклона стеблей, } \\
\text { высота растения }\end{array}$ \\
\hline RM463 & $12-я$ & $192(55)$ & Высота растения \\
\hline RM242 & 9-я & $225(55)$ & $\begin{array}{l}\text { Длина и толщина корневой системы, } \\
\text { устойчивость к холоду, отзывчивость на } \\
\text { культуру тканей, энергия прорастания, } \\
\text { стабильность клеточных мембран, высота } \\
\text { растения }\end{array}$ \\
\hline RM3276 & 4-я & $163(50)$ & Солеустойчивость \\
\hline RM5508 & 7-я & $177(50)$ & Солеустойчивость \\
\hline & В $ф$ а 3 у & проростков по призна & признаку《длина стебля» \\
\hline RM574* & 5 -я & $155(55)$ & Параметры корней \\
\hline RM154* & 2-я & $183(61)$ & Фотосинтетический потенциал \\
\hline RM141 & $6-я$ & $136(55)$ & Фотосинтетический потенциал \\
\hline RM82 & $7-я$ & $186(55)$ & $\begin{array}{l}\text { Фотосинтетический потенциал, } \\
\text { устойчивость к низким температурам }\end{array}$ \\
\hline RM286 & $11-я$ & $110(55)$ & $\begin{array}{l}\text { Период вегетации, фотосинтетический } \\
\text { потенциал }\end{array}$ \\
\hline RM227 & $3-я$ & $106(55)$ & $\begin{array}{l}\text { Параметры листового аппарата, энергия } \\
\text { прорастания, период вегетации, сухая } \\
\text { масса корневой системы }\end{array}$ \\
\hline RM24 & $1-я$ & $192(55)$ & $\begin{array}{l}\text { Отношение числа корней к количеству } \\
\text { побегов, период вегетации, параметры } \\
\text { листового аппарата }\end{array}$ \\
\hline RM542 & 7-я & $113(55)$ & Масса корней, высота растения \\
\hline RM126 & 8 -я & $171(55)$ & $\begin{array}{l}\text { Способность к осмотической регуляции, } \\
\text { период вегетации, старение листьев }\end{array}$ \\
\hline
\end{tabular}

С неспецифическими локусами, определяющими адаптивность к засолению в фазу проростков, сцеплены маркеры RM463, RM245, RM242, RM3276, RM5508, RM574, RM542. Маркеры RM463, RM242 связаны с генами, определяющими фотосинтетический потенциал посева. Маркер RM242 расположен в хромосомном регионе, где локализованы гены, определяющие адаптивность к стрессам за счет повышения устойчивости клеточных мембран и скорости роста. Маркеры RM574, RM542 и RM242 фланкируют локусы, которые определяют длину, толщину, объем и эффективность работы корней, иными словами, тоже повышают отзывчивость на фон минерального питания (77-79).

Микросателлитные маркеры, ассоциированные с интенсивностью роста проростка. Большинство локусов, определяющих скорость роста у представителей отечественного генофонда риса, по нашим данным (76), мономорфны, поскольку долгое время для борьбы с сорняками на посевах этой культуры в России использовали глубокий слой воды, 
быстрое прохождение которого обеспечивает дружные всходы сорта и дальнейшую высокую урожайность. Тем не менее статистический анализ позволил выявить полиморфные районы хромосом, определяющие скорость роста отечественных сортов. На сайте http://www.gramene.org опубликованы данные, которые показывают, что в выявленных локусах уже были обнаружены гены, ассоциированные с формированием корневой системы и энергией прорастания (табл. 3).

\section{SSR маркеры для кластеризации российских сортов риса по признакам, опре- деляющим скорость роста (76)}

\begin{tabular}{|c|c|c|c|}
\hline SSR маркер & Хромосома & $\begin{array}{l}\text { Продукт ампли- } \\
\text { фикации, п.н. }\end{array}$ & Признаки \\
\hline \multicolumn{4}{|c|}{$\begin{array}{cc}\text { Д л и н а } & \text { зароды ш е в о го с с е бля я } \\
108 & \text { Размеры стебля и листьев, энергия роста } \\
& \text { Д л и н а к о р н я }\end{array}$} \\
\hline RM242 & 9-я & 225 & $\begin{array}{l}\text { Толерантность к низким температурам, активность и размер } \\
\text { корневой системы и ее длина по отношению к числу и } \\
\text { размерам побегов и листьев, дифференциция эксплантов, } \\
\text { толерантность к стрессам мембранного комплекса, скорость } \\
\text { прорастания }\end{array}$ \\
\hline RM126 & 4-я & $\mathrm{Macc}$ & $\begin{array}{l}\text { Адаптивность к недостатку поливной воды, толерантность к } \\
\text { низким температурам, размер корневой системы и ее длина } \\
\text { по отношению к размерам побегов } \\
\text { a п р о р о с т к о в }\end{array}$ \\
\hline RM405 & $5-я$ & 110 & Длина стебля и метелки, размеры листьев \\
\hline RM261 & 4-я & 125 & $\begin{array}{l}\text { Засухоустойчивость, толерантность к низким температурам, } \\
\text { длина стебля и корня, метелки, размеры листьев }\end{array}$ \\
\hline RM242 & 9-я & 225 & $\begin{array}{l}\text { Отзывчивость на культивирование тканей, размеры корня, } \\
\text { его активность и длина по отношению к таковым стебля и } \\
\text { метелки, толерантность к низким температурам скорость про- } \\
\text { растания, толерантность к стрессам мембранного комплекса }\end{array}$ \\
\hline RM463 & $12-я$ & 192 & Размер надземных органов \\
\hline RM6314 & 4-я & 169 & Нет сведений \\
\hline
\end{tabular}

В районе локализации выявленных нами маркеров расположены гены, определяющие энергию прорастания, устойчивость к засухе, толерантность к низким температурам, морфотип и размеры корневой системы, отношение массы надземной к подземной части растения, стабильность мембран клеток в условиях стресса $(30,56,76)$. Формирование стебля, по нашим данным, определяли локусы, сцепленные с маркером RM289. В зоне его локализации расположены гены, оказывающие влияние на скорость прорастания, высоту растения, дифференциацию эксплантов, относительную массу корневой системы, скорость образования проростков $(39,40)$. Различия при кластеризации сортов с контрастными темпами роста проростка были достоверны (p $\leq$ 0,05) для маркеров RM261, RM405, RM463, RM242 и RM6314, расположенных соответственно на 4-й, 5-й, 9-й и 12-й хромосомах (см. табл. 3).

Мы обнаружили связь скорости роста проростка со многими локусами, определяющими адаптивность к абиотическим стрессам (76). Интенсивный рост, высокая фотосинтетическая активность и эффективность минерального питания повышают жизнеспособность растения и позволяют максимально быстро проходить фазы, чувствительные к стрессу, что сокращает вероятность повреждения экстремальными температурами или другими факторами, снижающими жизнеспособность, в том числе при органическом земледелии (80-83). При получении сортов для органического земледелия, обладающих устойчивой продуктивностью, наиболее перспективно селекционное повышение неспецифической адаптивности $(84,85)$.

Таким образом, сорта риса для органического земледелия должны обладать высокой адаптивностью к биотическим и абиотическим стрессам, 
конкурентоспособностью генотипа, эффективностью минерального питания и фотосинтеза. Высокая конкурентоспособность генотипа - комплексный признак, включающий высокую скорость роста, эффективное побегообразование, морфотип, обеспечивающий минимальное затенение в плотном посеве, формирование корневой системы с высокой поглощающей способностью. Для достижения устойчивой продуктивности в органическом земледелии наиболее перспективны сорта с неспецифической адаптивностью. Она определяется эффективной работой нескольких генетических систем, контролирующих фотосинтез, эффективность минерального питания, высокую скорость роста и развития, устойчивость к засолению. У российских сортов риса с локусами, контролирующими эффективность фотосинтеза, ассоциированы микросателлитные маркеры RM154, RM600, RM550, RM347, RM240, RM154 и RM509. Маркеры RM261, RM6314, RM126, RM463, RM405, RM509, RM242 дифференцируют образцы по эффективности минерального питания в фазу всходов, RM463, RM245, RM242, RM3276, RM5508, RM574, RM542 достоверно дискриминируют образцы на группы по солеустойчивости, полиморфизм по маркерам RM261, RM405, RM463, RM242 и RM6314 связан со скоростью роста проростка. Перечисленные молекулярные маркеры могут использоваться в программах селекции российских сортов риса для органического земледелия.

\section{ЛИТЕРАТУРА}

1. Lal R. Global potential of soil carbon sequestration to mitigate greenhouse effect. Critical Reviews in Plant Sciences, 2003, 22(2): 151-184 (doi: 10.1080/713610854).

2. Фадькин Г.Н., Виноградов Д.В., Щур А.В., Гогмачадзе Г.Д. Миграция азота в системе «удобрение-почва-растение» под влиянием длительного применения удобрений. АгроЭкоИнфо, 2015, 4: 1-12.

3. Шур А.В., Валько Д.В., Виноградов В.П. Экологические последствия развития интенсивного земледелия в Республике Беларусь. Проблемы региональной экологии, 2016, 3: 36-40.

4. Pimentel D., Hepperly P., Hanson J., Douds D., Seidel R. Environmental, energetic, and economic comparisons of organic and conventional farming systems. Bioscience, 2005, 55(7): 573582 (doi: 10.1641/0006-3568(2005)055[0573:EEAECO]2.0.CO;2).

5. Greene C. U.S. organic farming emerges in the 1990s: adoption of certified systems. Agriculture Information Bulletin, 2001, No. 770. Режим доступа: https://www.ers.usda.gov/webdocs/publications/42396/31544_aib770_002.pdf?v=2234.6. Без даты.

6. Uphoff N., Altieri M. Alternatives to conventional modern agriculture for meeting world needs in the next century (Report of a conference on sustainable agriculture, evaluation of new paradigms and old practices, April 26-30, 1999, Bellagio, Italy). Cornell International Institute for Food, Agriculture and Development, Ithaca, NY, 1999.

7. Hokazono S., Hayashi K. Variability in environmental impacts during conversion from conventional to organic farming: a comparison among three rice production systems in Japan. Journal of Cleaner Production, 2012, 28: 101-112 (doi: 10.1016/j.jclepro.2011.12.005).

8. Марцинкявичене А., Богужас В., Балните С., Пупалене Р., Величка Р. Влияние севооборотов, промежуточных посевов и органических удобрений на ферментативную активность почвы и содержание гумуса в органическом земледелии. Почвоведение, 2013, 2: 219-225 (doi: 10.7868/S0032180X1302010X).

9. Ходус А.В. Хозяйствовать экологически можно уже сейчас! На пути к устойчивому развитию России, 2004, 28: 3-7.

10. Кондратьева И.В., Ходус А.В. Эко-сертификация: путь к ответственному биорынку. $H a$ пути к устойчивому развитию России, 2004, 28: 7-9.

11. Полушкина Т.М. Органическое сельское хозяйство в системе устойчивого развития сельских территорий. Проблемы теории и практики управления, 2016, 3: 133-142.

12. Старовойтова Н.П. Органическое земледелие в России: плюсы и минусы. Бизнес. Образование. Право. Вестник Волгоградского института бизнеса, 2015, 4(33): 226-230.

13. Bayramoglu Z., Gundogmus E. Cost efficiency on organic farming: a comparison between organic and conventional raisin-producing households in Turkey. Spanish Journal of Agricultural Research, 2008, 6(1): 3-11.

14. Cavigelli M., Hima B., Hanson J., Teasdale J., Conklin A., Lu Y. Long-term economic 
performance of organic and conventional field crops in the mid-Atlantic region. Renewable Agriculture and Food Systems, 2009, 24(2): 102-119 (doi: 10.1017/S1742170509002555).

15. Hazra K.K., Swain D.K., Bohra A., Singh S.S., Kumar N., Nath C. P. Organic rice: potential production strategies, challenges and prospects. Organic Agriculture, 2018, 8: 39-56 (doi: 10.1007/s13165-016-0172-4).

16. Харитонов Е.М., Очкас Н.А., Гончарова Ю.К., Шелег В.А. Сорта риса для органического и традиционного земледелия. Рисоводство, 2019, 44(3): 50-56.

17. Lotter D., Seidel R., Liebhardt W. The performance of organic and conventional cropping systems in an extreme climate year. American Journal of Alternative Agriculture, 2003, 18(3): 146-154 (doi: 10.1079/AJAA200345).

18. Hanson J., Lichtenberg E., Peters S. Organic versus conventional grain production in the midAtlantic. An economic overview and farming system overview. American Journal of Alternative Agriculture, 1997, 12(1): 2-9 (doi: 10.1017/S0889189300007104).

19. Ковалев Н.Г., Барановский И.Н. Органические удобрения в ХХІ веке (Биоконверсия органического сырья). Тверь, 2006.

20. Уваров Р.А. Результаты исследований потерь питательных веществ при биоконверсии подстилочного птичьего помета в биоферментационной установке камерного типа. Технологии и технические средства механизированного производства продукции растениеводства и животноводства, 2015, 86: 139-147.

21. Dorais M. Organic production of vegetables: state of the art and challenges. Canadian Journal of Plant Science, 2008: 1055-1066 (doi: 10.4141/CJPS07160).

22. Hepperly P., Seidel R., Pimentel D., Hanson J., Douds D. Jr. Organic farming enhances soil carbon and its benefits. In: Soil carbon management/J.M. Kimble, C.W. Rice, D. Reed, S. Mooney, R.F. Follett, R. Lal (eds.). CRC Press, Boca Raton, FL, USA, 2019: 129-153.

23. Teasdale J., Coffman C., Mangum R. Potential long-term benefits of no-tillage and organic cropping systems for grain production and soil improvement. Agronomy Journal, 2000, 99(5): 12971305 (doi: 10.2134/agronj2006.0362).

24. Moyer J., Nichols K., Bhosekar V. Fifteen year review summarizing effects of conventional and organic farming Systems on soils, nutrition, environment, economics and yields (1981-1995). Asian Journal of Science and Technology, 2017, 8(4): 4628-4634 (doi: 10.19080/ARTOAJ.2017.06.555678).

25. Fedulova E.A., Medvedev A.V., Kosinskiy P.D., Kononova S.A., Pobedash N. Modeling of the agribusiness enterprise activity on the basis of the balanced scorecard. Foods and Raw Materials, 2016, 4(1): 154-162 (doi: 10.21179/2308-4057-2016-1-154-162).

26. Goncharova J.K., Kharitonov E.M. Rice tolerance to the impact of high temperatures. In: Agricultural research updates, V. 9. Nova Science Publishers, Inc., NY, 2015: 97-125.

27. Chavas J., Posner J., Hedtcke J. Organic and conventional production systems in the Wisconsin Integrated Cropping Systems Trial: II. Economic and risk analysis 1993-2006. Agronomy Journal, 2009, 101(2): 288-295 (doi: 10.2134/agronj2008.0055x).

28. Воронкова Н.А., Хамова О.Ф. Агроэкологическая оценка влияния предшественников на элементы плодородия чернозема выщелоченного и урожайность яровой мягкой пшеницы. Вестник Алтайского государственного аграрного университета, 2009, 5: 24-29.

29. Доброхотов С.А., Анисимов А.И. Использование сортов, сидератов, минеральных удобрений, микроэлементов и биопрепаратов для повышения урожайности озимых зерновых в органическом земледелии. Мат. Межд. науч.-практ. конф. «Развитие земледелия в Нечерноземье: проблемы и их решение». СПб, 2016: 119-124.

30. Goncharova J.K., Kharitonov E.M. Genetic control of traits determining phosphorus uptake by rice varieties (Oryza sativa L.). Vavilov Journal of Genetics and Breeding, 2015, 19(2): 197-204.

31. Lammerts van Bueren E.T. Challenging new concepts and strategies for organic plant breeding and propagation. Proceedings of the EUCARPIA Meeting on Leafy Vegetables Genetics and Breeding, Noordwijkerhout, The Netherlands /Th.J.L. van Hintum, A. Lebeda, D. Pink, J.W. Schut (eds.). Centre for Genetic Resources, The Netherlands (CGN), Wageningen, The Netherlands, 2003: 17-22.

32. Lammerts van Bueren E.T., Struik P.C., Jacobsen E. Ecological concepts in organic farming and their consequences for an organic crop ideotype. NJAS - Wageningen Journal of Life Sciences, 2002, 50(1): 1-26 (doi: 10.1016/S1573-5214(02)80001-X).

33. Morris M.L., Bellon M.R. Participatory plant breeding research: Opportunities and challenges for the international crop improvement system. Euphytica, 2004, 136: 21-35 (doi: 10.1023/b:euph.0000019509.37769.b1).

34. Mader P., Fliessbach A., Dubois D., Gunst L., Fried P., Niggli U. Soil fertility and biodiversity in organic farming. Science, 2004, 296(5573): 1694-1697 (doi: 10.1126/science.1071148).

35. Seufert V., Ramankutty N., Foley J.A. Comparing the yields of organic and conventional agriculture. Nature, 2012, 485: 229-232 (doi: 10.1038/nature11069).

36. Swer H., Dkhar M.S., Kayang H. Fungal population and diversity in organically amended agricultural soils of Meghalaya, India. Journal of Organic Systems, 2011, 6(2): 3-12. 
37. Van Bruggen A.H. Plant disease severity in high-input compared to reduced-input and organic farming systems. Plant Disease, 1995, 79: 976-984 (doi: 10.1094/PD-79-0976).

38. Heyden B., Lammerts van Bueren E.T. Bio-diversity of vegetables and cereals - chances for developments in organic agriculture. Naturschutzbund (NABU), Bonn, 2000.

39. Leu A. Ameliorating the effects of climate change with organic systems. Journal of Organic Systems, 2009, 4(1): 4-7.

40. Vanaja T., Mammootty K.P. 'Kuthiru' and 'Orkayama' - newly identified genetic resources from Kerala, India for salinity tolerance in Indica rice. Nature Proceedings, 2010 (doi: 10.1038/npre.2010.4561.1).

41. Longping Y. Breeding of super hybrid rice. Proc. Int. rice research conference «Rice Research for food security and poverty alleviation»/S. Peng, B. Hardy (eds.). International Rice Research Institute, Los Bacos, Laguna (Philippines), 2001: 143-149.

42. Zhang O. Strategies for developing green super rice. Proceedings of the National Academy of Sciences, 2007, 104(42): 16402-16409 (doi: 10.1073/pnas.0708013104).

43. Vanaja T., Mammootty K.P., Govindan M. Development of organic indica rice cultivar (Oryza sativa L.) for the wetlands of Kerala. India through new concepts and strategies of crop improvement. Journal of Organic Systems, 2013, 8(2): 18-28.

44. Tammis W.L.M., van den Brink W.J. Conventional, integrated and organic winter wheat production in the Netherlands in the period 1993-1997. Agriculture, Ecosystems and Environment, 1999, 76(1): 47-59.

45. Lammerts van Bueren E.T., Jones S.S., Tamm L., Murphy K.M., Myers J.R., Leifert C., Messmer M.M. The need to breed crop varieties suitable for organic farming, using wheat, tomato and broccoli as examples: a review. NJAS - Wageningen Journal of Life Sciences, 2011, 58(3-4): 193-205 (doi: 10.1016/j.njas.2010.04.001).

46. Харитонов Е.М., Гончарова Ю.К., Очкас Н.А., Шелег В.А., Болянова С.В. Применение многомерных методов для разделения сортов риса по реакции на изменение условий среды. Сельскохозяйственная биология, 2017, 52(1): 152-160 (doi: 10.15389/agrobiology.2017.1.152rus).

47. Goncharova J.K., Gontcharov S.V., Chicharova E.E. Localization of chromosome regions controlling high photosynthetic potential in Russian rice cultivars. Russian Journal of Genetics, 2018, 54(7): 796-804 (doi: 10.1134/S1022795418070037).

48. Akhtar N., Nazir M.F., Rabnawaz A., Mahmood T., Safdar M.E., Asif M., Rehman A. Estimation of heritability, correlation and path coefficient analysis in fine grain rice. The Journal of Animal \& Plant Sciences, 2011, 21(4): 660-664.

49. Kumar C. Correlation and path coefficient analysis of yield components in aerobic rice (Oryza sativa L.). The Bioscan, 2014, 9(Supplement on Genetics and Plant Breeding): 907-913.

50. Nagaraju C., Sekhar R.M., Reddy H.K., Sudhakar P. Correlation between traits and path analysis coefficient for grain yield and other components in rice (Oryza sativa L.) genotypes. International Journal of Applied Biology and Pharmaceutical Technology, 2013, 4(3): 137-142.

51. Ramakrishnan S.H., Anandakumar C.R, Saravanan S., Malini N. Association analysis of some yield traits in rice (Oryza sativa L.). Journal of Applied Sciences Research, 2006, 2(7): 402-404.

52. Deshpande H.H., Devasenapathy P. Effect of green manuring and organic manures on yield, quality and economics of rice (Oryza sativa L.) under lowland condition. Karnataka Journal of Agricultural Sciences, 2010, 23(2): 235-238.

53. Dhurai S.Y., Reddy D.M., Bhati B.K. Correlation and path coefficient analysis for yield and quality traits under organic fertilizer management in rice (Oryza sativa L.). Electronic Journal of Plant Breeding, 2014, 5(3): 581-587.

54. Zahid M.A., Akhtar M., Sabir M., Manzoor Z., Awan T.H. Correlation and path analysis studies of yield and economic traits in Basmati rice (Oryza sativa L.). Asian Journal of Plant Sciences, 2006, 5(4): 643-645 (doi: 10.3923/ajps.2006.643.645).

55. Ali J., Jewel Z.A., Mahender A., Anandan A., Hernandez J., Li Z. Molecular genetics and breeding for nutrient use efficiency in rice. Rice breeding platform. International Journal of Molecular Sciences Review, 2018, 19(6): 1762 (doi: 10.3390/ijms19061762).

56. Гончарова Ю.К., Харитонов Е.М., Шелег В.А., Болянова С.В. Влияние морфологии корневой системы на адаптивность риса к недостатку элементов минерального питания. Российская сельскохозяйственная наука, 2016, 6: 3-8.

57. Zhang Y.J., Dong Y.J., Zhang J.Z., Xiao K., Xu J.L., Terao H. Mapping QTLs for deficiency phosphorus response to root-growth of rice seedling. Rice Genetics Newsletter, 2006, 25: 36-37.

58. Manjunatha G.A., Saravana Kumar M., Jayashree M. Character association and path analysis in rice (Oryza sativa L.) genotypes evaluated under organic management. Journal of Pharmacognosy and Phytochemistry, 2017, 6(6): 1053-1058.

59. Hemamalini G.S., Shashidhar H.E., Hittalmani S. Molecular marker assisted tagging of morphological and physiological traits under two contrasting moisture regimes at peak vegetative stage in 
rice (Oryza sativa L.). Euphytica, 2000, 112: 69-78 (doi: 10.1023/A:1003854224905).

60. Yue B., Xue W.Y., Xiong L.Z., Yu X.Q., Luo L.J., Cui K.H., Jin D.M., Xing Y.Z., Zhang Q.F. Genetic basis of drought resistance at reproductive stage in rice: separation of drought tolerance from drought avoidance. Genetics, 2006, 172: 1213-1228 (doi: 10.1534/genetics. 105.045062).

61. Robin S., Pathan M.S., Courtois B., Lafitte R., Carandang C., Lanceras S., Amante M., Nguyen H.T., Li Z. Mapping osmotic adjustment in an advanced back-cross inbred population of rice. Theoretical and Applied Genetics, 2003, 107: 1288-1296 (doi: 10.1007/s00122-003-1360-7).

62. Jiang G.H., He Y.Q., Xu C.G., Li X.H., Zhang Q. The genetic basis of stay-green in rice analyzed in a population of doubled haploid lines derived from an indica by japonica cross. Theoretical and Applied Genetics, 2004, 108: 688-698 (doi: 10.1007/s00122-003-1465-z).

63. Kharitonov E.M., Goncharova Y.K., Maliuchenko E.A. Genetics of the traits determining adaptability to abiotic stress in rice (Oryza sativa L.). Russian Journal of Genetics: Applied Research, 2017, 7(6): 684-697 (doi: 10.1134/S2079059717060089).

64. McCouch S.R., Teytelman L., Xu Y., Lobos K.B., Clare K., Walton M., Fu B., Maghirang R., Li Z., Xing Y., Zhang Q., Kono I., Yano M., Fjellstrom R., DeClerck G., Schneider D., Cartinhour S., Ware D., Stein L. Development and mapping of 2240 new SSR markers for rice (Oryza sativa L.) (supplement). DNA Research, 2002, 9(6): 257-279 (doi: 10.1093/dnares/9.6.257).

65. Temnykh S., DeClerck G., Lukashova A., Lipovich L., Cartinhour S., McCouch S. Computational and experimental analysis of microsatellites in rice (Oryza sativa L.): frequency, length variation, transposon associations, and genetic marker potential. Genome Research, 2001, 11: 1441-1452 (doi: 10.1101/gr.184001).

66. Choi Y.H., Lee S.J., Yoon D.B., Moon H.P., Ahn S.N. Mapping of quantitative trait loci for cold tolerance in weedy rice. Breeding Science, 2004, 54: 373-380 (doi: 10.1270/jsbbs.54.373).

67. Mahender A., Anandan A., Pradhan S.K., Singh O.N. Traits-related QTLs and genes and their potential applications in rice improvement under low phosphorus condition. Archives of Agronomy and Soil Science, 2017, 64(4): 449-464 (doi: 10.1080/03650340.2017.1373764).

68. Berry P.M., Sylvester-Bradley R., Philipps L., Hatch D.H., Cuttle S.P., Rayns F.W., Gosling P. Is the productivity of organic farms restricted by the supply of available nitrogen? Soil Use and Management, 2002, 18(s1): 248-255 (doi: 10.1111/j.1475-2743.2002.tb00266.x).

69. Bhadoria P.B.S., Prakash Y.S., Kar S., Rakshit A. Relative efficacy of organic manures on rice production in lateritic soil. Soil Use and Management, 2003, 19(1): 80-82 (doi: 10.1111/j.14752743.2003.tb00283.x).

70. Bhattacharyya P., Chakraborty A., Bhattacharya B., Chakrabarti K. Evaluation of MSW compost as a component of integrated nutrient management in wetland rice. Compost Science \& Utilization, 2003, 11(4): 343-350 (doi: 10.1080/1065657X.2003.10702144).

71. Bi L., Zhang B., Liu G., Li Z., Liu Y., Ye C., Yu X., Lai T., Zhang J., Yin J., Liang Y. Long-term effects of organic amendments on the rice yields for double rice cropping systems in subtropical China. Agriculture, Ecosystems \& Environment, 2009, 129(4): 534-541 (doi: 10.1016/j.agee.2008.11.007).

72. Гончарова Ю.К., Харитонов Е.М. О генетико-физиологических механизмах солеустойчивости у риса (Oryza sativa L.) (обзор). Сельскохозяйственная биология, 2013, 3: 3-11 (doi: 10.15389/agrobiology.2013.3.3rus).

73. Champagne E.T., Bett-Garber K.L., Grimm C.C., McClung A.M. Effects of organic fertility management on physicochemical properties and sensory quality of diverse rice cultivars. Cereal Chemistry, 2007, 84(4): 320-327 (doi: 10.1094/cchem-84-4-0320).

74. Champagne E.T., Bett-Garber K.L., Thomson J.L., Fitzgerald M.A. Unravelling the impact of nitrogen nutrition on cooked rice flavor and texture. Cereal Chemistry, 2009, 86(3): 274-280 (doi: 1010.1094/CCHEM-86-3-0274).

75. Hoad S., Topp C., Davies K. Selection of cereals for weed suppression in organic agriculture: a method based on cultivar sensitivity to weed growth. Euphytica, 2008, 163(3): 355-366 (doi: 10.1007/s10681-008-9710-9).

76. Харитонов Е.М., Гончарова Ю.К., Гончаров С.В., Бруяко В.Н. Молекулярное маркирование локусов, определяющих высокие темпы роста на начальных этапах развития растений у российских сортов риса (Oryza sativa L.). Сельскохозяйственная биология, 2019, 54(5): 892904 (doi: 10.15389/agrobiology.2019.5.892rus).

77. Baldani J.I., Baldani V., Seldin L., Döbereiner J. Characterization of Herbaspirillum seropedicae gen. nov., sp. nov., a root-associated nitrogen-fixing bacterium. International Journal of Systematic and Evolutionary Microbiology, 1986, 36(1): 86-93 (doi: 10.1099/00207713-36-1-86).

78. Chi F., Shen S.-H., Cheng H.-P., Jing Y.-X., Yanni Y.G., Dazzo F.B. Ascending migration of endophytic rhizobia, from roots to leaves, inside rice plants and assessment of benefits to rice growth physiology. Applied and Environmental Microbiology, 2005, 71(11): 7271-7278 (doi: 10.1128/AEM.71.11.7271-7278.2005).

79. Feng B., Chen K., Cui Y., Wu Z., Zheng T., Zhu Y., Ali J., Wang B., Xu J., Zhang W., 
Li Z. Genetic dissection and simultaneous improvement of drought and low nitrogen tolerances by designed QTL pyramiding in rice. Frontiers in Plant Science, 2018, 9(9): 306 (doi: 10.3389/fpls.2018.00306).

80. Huang L., Jun Y.U., Jie Y.A., Zhang R., Yanchao B.A., Chengming S.U., Zhuang H. Relationships between yield, quality and nitrogen uptake and utilization of organically grown rice varieties. Pedosphere, 2016, 26(1): 85-97 (doi: 10.1016/S1002-0160(15)60025-X).

81. Jeyabal A., Kuppuswamy G. Recycling of organic wastes for the production of vermicompost and its response in rice-legume cropping system and soil fertility. European Journal of Agronomy, 2001, 15(3): 153-170 (doi: 10.1016/S1161-0301(00)00100-3).

82. Yorobe J.M. Jr., Ali J., Pede V., Rejesus R.M., Velarde O.P., Wang W. Yield and income effects of rice varieties with tolerance of multiple abiotic stresses: the case of green super rice (GSR) and flooding in the Philippines. Agricultural Economics, 2016, 47(3): 261-271 (doi: 10.1111/agec.12227).

83. Van Quyen N., Sharma S.N. Relative effect of organic and conventional farming on growth, yield and grain quality of scented rice and soil fertility. Archives of Agronomy and Soil Science, 2003, 49(6): 623-629 (doi: 10.1080/03650340310001612979).

84. Xu M.-G., Li D.-C., Li J.-M., Qin D.-Z., Kazuyuki Y., Hosen Y. Effects of organic manure application with chemical fertilizers on nutrient absorption and yield of rice in Hunan of Southern China. Agricultural Sciences in China, 2008, 7(10): 1245-1252 (doi: 10.1016/S1671-2927(08)60171-6).

85. Zheng J., Zhang X., Li L., Zhang P., Pan G. Effect of longterm fertilization on C mineralization and production of $\mathrm{CH}_{4}$ and $\mathrm{CO}_{2}$ under anaerobic incubation from bulk samples and particle size fractions of a typical paddy soil. Agriculture, Ecosystems \& Environment, 2007, 120(2-4): 129-138 (doi: 10.1016/j.agee.2006.07.008).

\author{
1 ФГБНУ Федеральный научный центр риса, \\ 350921 Россия, г. Краснодар, п/о Белозерный, 3, \\ e-mail: yuliya_goncharova_20@mail.ru $₫$, evgeniyharitonov46@mail.ru, \\ gapishko1979@mail.ru; \\ 2000 «Аратай», \\ 143026 Россия, г. Москва, Сколково, ул. Нобеля, 7, \\ e-mail: ochkasnikolay@mail.ru; \\ ЗФГБОУ ВО Кубанский ГАУ им. И.Т. Трубилина, \\ 350044 Россия, г. Краснодар, ул. Калинина, 13, \\ e-mail: neschadim.n@kubsau.ru
}

Поступила в редакцию 4 июня 2020 года

Sel’skokhozyaistvennaya biologiya [Agricultural Biology], 2020, V. 55, № 5, pp. 847-860

\title{
FEATURES OF RICE (Oryza sativa L.) VARIETIES FOR ORGANIC FARMING IN CONNECTION WITH MARKER ASSISTED BREEDING (review)
}

\author{
Yu.K. Goncharova1, ${ }^{\bowtie}$, E.M. Kharitonov' ${ }^{1}$, N.A. Ochkas ${ }^{1,2}$, N.I. Gapishko', \\ H.H. Neschadim ${ }^{3}$
}

${ }^{1}$ Federal Rice Research Center, 3, Belozernii, Krasnodar, Russia 350921, e-mail yuliya_goncharova_20@mail.ru (corresponding author $\bowtie)$, evgeniyharitonov46@mail.ru, gapishko1979@mail.ru;

${ }^{2}$ LLC Aratay Skolkovo, 7, ul. Nobelya, Moscow, Russia 143026, e-mail ochkasnikolay@mail.ru;

2Trubilin Kuban State Agrarian University, 13, ul. Kalinina, Krasnodar, Russia 350044, e-mail neschadim.n@kubsau.ru ORCID:

Goncharova J.K. orcid.org/0000-0003-2643-7342

Kharitonov E.M. orcid.org/0000-0002-4049-6173

Gapishko N.I. orcid.org/0000-0002-3695-3001

Ochkas N.A. orcid.org/0000-0003-4852-3356

The authors declare no conflict of interests

Acknowledgements:

Supported financially from Russian Science Foundation, grant No. 19-16-00064

Received June 4, 2020

doi: 10.15389 /agrobiology.2020.5.847eng

\begin{abstract}
Organic agriculture is actively developing worldwide with a $30 \%$ annual increase (S.Y. Dhurai et al., 2014). Today, the market for organic products reaches more than $\$ 200$ billion a year. Products grown by organic farming technologies cost $20 \%$ and sometimes $100 \%$ higher. However, decrease in crop yields in organic farming largely eliminates the cost advantage (G.N. Fadkin et al., 2015). The use of specialized varieties should increase the profitability of organic farming (V. Seufert et al., 2012). However, there is still no clear separation in generating breeding material for these technologies. Purpose of this work is to review characteristics that must be selected when creating rice varieties for organic farming and effective working methods. Variety
\end{abstract}


for this technology should possess a number of characteristics, i.e. high adaptability to biotic and abiotic stresses, competitiveness of the genotype, efficiency of mineral nutrition and photosynthesis (T. Vanaja et al., 2013). Note, all of these traits are complex and largely interconnected. So, the competitiveness of the genotype is ensured by a number of features, i.e. high growth rate; effective shoot formation (tillering); morphotype with minimal shading in dense crops; high efficiency of photosynthesis for the full use of solar energy; high root absorption (E.T. van Bueren et al., 2011; J.K. Goncharova et al., 2018). Increasing specific adaptability to a complex of stresses requires more effort and does not guarantee a result due to a significant decrease in the effect of individual genes resulted from intralocus and intergenic interactions. In nature, a complex of factors acts on the plant, which depreciates specific adaptability. Specific resistance to pathogens, as a rule, is overcome in a very short time (A.H. Bruggen, 1995). The great promise of increasing the overall adaptability of plant due to non-specific adaptability is shown. The most polymorphic loci of the Russian rice varieties for non-specific adaptability associated with the efficiency of genetic systems providing the growth rate, photosynthesis, mineral nutrition are summarized (L. Huang et al., 2016). Intensive growth, high photosynthetic activity and the effectiveness of mineral nutrition increase the vitality, allow plants to pass stress sensitive phases as quickly as possible, which reduces the likelihood of damage caused by extreme temperatures or other factors that reduce viability, including during organic farming. In Russian rice varieties, Microsatellite markers RM154, RM600, RM550, RM347, RM240, RM154, and RM509 are associated with loci for the efficiency of photosynthesis, RM261, RM6314, RM126, RM463, RM405, RM509, RM242 are associated with loci for mineral nutrition, RM463, RM245, RM242, RM3276, RM5508, RM574, RM542 are associated with salt resistance, and RM261, RM405, RM463, RM242, RM6314 are linked to loci for seedling growth rates. The markers identified by us are located in the same chromosome regions as the genes that determine the germination energy, drought resistance, tolerance to low temperatures, the morphotype and size of the root system, the ratio of the aboveground to the underground part of the plant, the stability of cell membranes under stress conditions, and the photosynthetic potential of the variety (G.A. Manjunatha et al., 2017; J. Ali et al., 2018).

Keywords: rice, adaptability, abiotic stresses, drought, salinization, non-specific resistance, mineral nutrition, organic farming. 